\title{
Immunohistochemical staining of leptin is associated with grade, stage, lymph node involvement, recurrence, and hormone receptor phenotypes in breast cancer
}

Mohamad Nidal Khabaz ${ }^{1}$, Amer Abdelrahman, Nadeem Butt², Lila Damnhory ${ }^{3}$, Mohamed Elshal', Alia M. Aldahlawi ${ }^{4}$, Swsan Ashoor ${ }^{5}$, Basim Al-Maghrabi ${ }^{6}$, Pauline Dobson 7 , Barry Brown ${ }^{7}$, Kaltoom Al-Sakkaf ${ }^{3}$, Mohmmad Al-Qahtani ${ }^{8}$ and Jaudah Al-Maghrabi ${ }^{9^{*}}$ (D)

\begin{abstract}
Background: Obesity is part of the established risk factors for breast cancer (BC) in postmenopausal females. Circulating leptin increases in parallel with the increase of body weight and fat reservoir.

Methods: This research investigated the link between leptin phenotype and the clinicopathological factors in BC. A large set of breast cancer cases (449), and 27 non-cancerous tissue samples of breast were employed for leptin expression recognition using immunohistochemistry staining.

Results: Cytoplasmic immunohistochemical staining of leptin was recognized in 376 (83.7\%) and 25 (92.6\%) of BC and control cases respectively. Leptin immunostaining were significantly associated with age, histotypes, grade, stage, lymph node involvement, tumor recurrence, hormone receptor phenotypes, ER and HER2 expressions, and $p$-values were $(P=0.0233),(P=0.0001),(P=0.050),(P=0.0291),(P=0.0300),(P=0.0023),(P=0.0021)$, $(P=0.0279)$ respectively. Reasonable proportion of cases with low staining score was more prevalent in all subgroups of clinicopathological parameters except ER- PR+ HER2- hormone receptor phenotype and mucinous carcinoma which showed high level of leptin immunoreactivity. Tumor recurrence is less prevailing in high score leptin immunostaining cases. Furthermore, Log Rank (Mantel-Cox) test findings revealed considerably different survival distributions were observed for the different categories of leptin immunostaining scores $(P=0.032)$. Negative leptin immunostaining is related to poor survival.
\end{abstract}

Conclusions: Our preliminary findings support leptin clinical value in confirming BC diagnosis as well as prognosis. These results suggest that leptin molecule is an important biomarker that could identify type, grade, stage, lymph node involvement, relapse and prognosis in breast cancer.

Keywords: Leptin, Breast cancer, Immunohistochemistry

\footnotetext{
* Correspondence: jalmaghrabi@hotmail.com; jalmgrabi@kau.edu.sa

${ }^{9}$ Department of Pathology, Faculty of Medicine, King Abdulaziz University,

P.O. Box 80205, Jeddah 21589, Saudi Arabia

Full list of author information is available at the end of the article
} 


\section{Background}

Breast cancer $(\mathrm{BC})$ is a shattering tumor and an important cause of worldwide death [1]. Recently published data stated that breast neoplasms are the most frequent malignancy among females with approximately 1,700,000 new registered cases and around 580,000 demises of BC in the United States of America in 2015 according to the American Cancer Society [2]. In Saudi Arabia, BC has a comparable rank among cancers and neoplasms accounting for (25.8\%) of all registered neoplasms in females in 2012 as stated by the Saudi Cancer Registry [3].

$\mathrm{BC}$ has been distinguished as a high complex heterogeneous tumor with distinctive cellular origin and various histotypes, progression and metastatic potential [4]. Irrespective of noteworthy improvements in the diagnosis and treatment of $\mathrm{BC}$, the tumor is still considered a big challenge to clinicians due to bad prognosis and big recurrence proportion in some histotypes of BC particularly triple negative, for instance up to $40 \%$ of newly registered cases relapse in 5 years [5]. The management of $\mathrm{BC}$ is subject to the clinicopathological parameters of patients, such as grade and stage of cancer as measures of pleasant or bad prognosis. Nevertheless, these factors are not enough to guess the clinical consequences and worse yet, may produce variations in a cluster of neoplasms with the same grade or stage. This is essentially due to heterogeneity of $\mathrm{BC}$ cells [6]. Therefore, it is necessary to find novel diagnostic markers and medicinal modalities which help in the diagnosis and prognosis of $\mathrm{BC}$, enhance the stratification of high risk patients and improve clinical outcomes [7].

Leptin is one hundred and sixty seven amino acid residues molecule that is encrypted by the Obese gene $(\mathrm{Ob})$ [8]. It was expressed firstly in white adipose tissue; however, later it was found that other tissues express leptin such as the liver, ovaries, placenta, stomach, pituitary gland and skeletal muscles [9]. It is now established that leptin has several roles and counted a member of adipokines [10]. Many investigations have illustrated the function of leptin in tumor cells proliferation, movement, invasion and apoptosis inhibition [11-13]. Some other reports have examined leptin function in several tumor development risks, but the results are controversial $[14,15]$. Unquestionably definite proof is needed to elucidate leptin's exact function in the growth and progress of breast tumors, as perception of leptin correlation with breast cancer can improve our awareness of breast carcinogenesis and support improving management and preventive plans. Thus, the current study describes leptin immunoexpression in $\mathrm{BC}$ and evaluates the association between leptin phenotype and the clinical factors as well as follow-up data of breast cancer.

\section{Methods}

Four hundred fourty nine cases of BC and 27 control cases, which include fibroadenomas and normal breast tissue, were taken from the archive of pathological sciences department at King Abdulaziz University Hospital in Saudi Arabia. Sections from tumor paraffin blocks were hematoxylin and eosin stained and histologically evaluated. The unit of medical records provided us with patients' clinicopathological data (age, size, type, grade and stage of tumors) (Table 1). WHO recommendation regarding grade and stage of $\mathrm{BC}$ was applied. All tumors and control cases blocks were utilized in the production of tissue microarray. This study has met all the instruction and requirement of the ethical committee approval.

\section{Tissue microarray production (TMA)}

Four hundred fourty nine cases of $\mathrm{BC}$ and 27 control cases were used to assemble tissue microarray [16]. TMA blocks have been cut and placed on coated slides, then they have been immunohistochemically stained.

\section{Immunohistochemistry staining protocol}

Multimer molecule based scientific knowledge were employed in the immunohistochemistry staining of $\mathrm{BC}$ sections to apply anti-leptin rabbit polyclonal antibody with dilution ratio of 1 to 100 [catalog code: sc-842, Santa Cruz Biotechnology, USA), and ULTRAVIEW TM $\mathrm{DAB}$ visualizing protocol. Immunohistochemistry autostainer (BenchMark ULTRA, Ventana, Arizona, USA) was used for immunohistochemistry staining. Every staining run contained a slide treated with tris buffer in place of the $\mathrm{Ob}$ antibody as a negative control. Slide section of placenta tissue was employed as positive control. Cases with brown granular cytoplasmic stain in more than $5 \%$ of tumor cells were counted positive.

Leptin immunoreactivity has been scored, by two pathologists, for staining intensity and positively stained cells percentage. The frequency of positive cells was evaluated applying semiquantitative method in 3 fields with lenses of 40 amplification power. Leptin staining intensity has been given scores $0,1,2,3$ and 4 representing negative, weak, moderate and strong staining respectively. Scores of staining intensity has been presented as negative staining (0), low level immunoreactivity (1) and high level (2 and 3). When a disparity between the two pathologists' staining scores has happened, the lowest score value was reported.

\section{Statistical analysis}

All data were assessed statistically by IBM-SPSS software (version 21). All data values were presented as percentages and incidences. The association between clinicopathological factors of $\mathrm{BC}$ and leptin expression was explored statistically by chi-square test. Comparison of survival distributions for various leptin immunohistochemistry staining intensity levels was assessed applying Log Rank (Mantel-Cox) test in addition to Kaplan Meier 
Table 1 Describe the distribution of various clinicopathological variables with leptin immunostaining in breast cancer

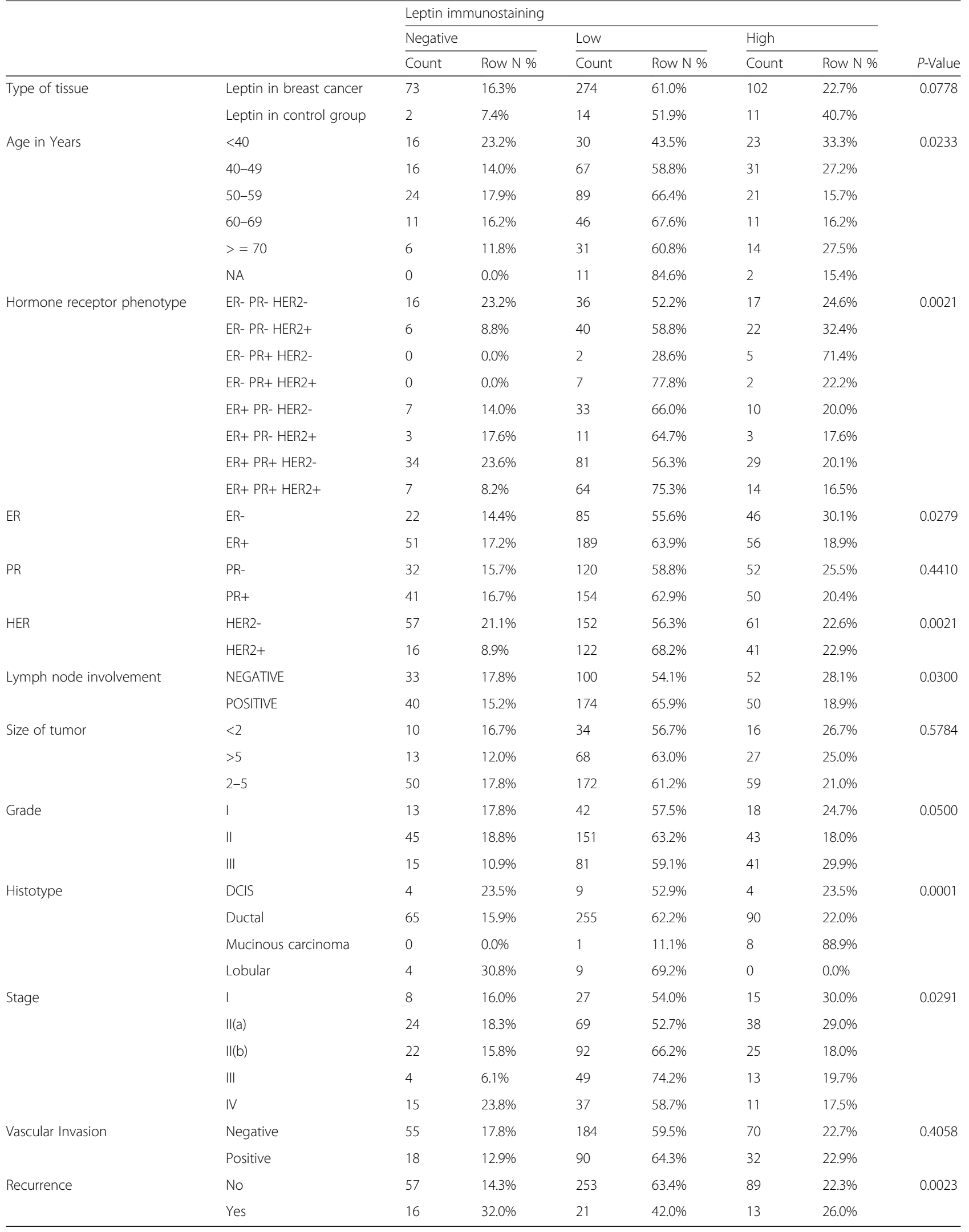


survival curves. The level of significance was counted when $P<0.05$.

\section{Results}

All $\mathrm{BC}$ cases were reviewed and their clinicopathological factors have been presented in Table 1. The histotypes of breast cancer cases of the current study, in descending order, were infiltrating ductal carcinoma, ductal carcinoma in situ, infiltrating lobular carcinoma and mucinous carcinoma which counted $91.3 \%, 3.8 \%, 2.9$ and $2 \%$ respectively (Table 1 ). The mean age of patients was 50.7 years varying from 24 to 94 years.

Brown granular cytoplasmic leptin immunoexpression was detected in the transformed epithelium of 376 (83.7\%) BC cases and 25 (92.6) cases of control group (Fig. 1).

Leptin expression did not show any statistical significant difference between $\mathrm{BC}$ and control cases. The distribution of leptin phenotypes which identified in $\mathrm{BC}$ transformed epithelial cells and its association with different clinicopathological variables were reported in Table 1. Percentage of positively stained cells ranged from $5 \%$ to $100 \%$ in breast tumors of the present study. About $40 \%$ of breast cancer cases showed leptin immunoreactivity in more than $50 \%$ of their transformed epithelial cells. Small fraction of cases $(<10 \%)$ showed moderate to strong leptin immunoreactivity in stromal cells; however, these cases were of no statistical significance.

Leptin immunostaining is significantly related with age $(P=0.0233)$, reasonable proportion of low scores staining is observed in all age groups. Breast cancer histotypes showed significant association with leptin immunostaining $(P=0.0001)$. DCIS, invasive ductal carcinoma and invasive lobular carcinoma histotypes showed more frequently low scores of leptin immunostaining while the vast majority of mucinous carcinomas were of high immunostaining scores. Grade of breast tumors is marginally significant with leptin immunostaining $(P=0.050)$. Grade II is more frequent with low leptin immunoreactivity. Breast carcinoma stage was also significantly associated with leptin expression $(P=0.0291)$. A considerable fraction of stage II (b) and stage III were found to be common with low leptin immunostaining. Significantly, more cases with metastases in lymph nodes were observed in low score staining $(P=0.0300)$. Tumor recurrence was significantly associated with cases of low leptin immunostaining scores $(P=0.0023)$. Recurrence is less prevailing in cases with high score of leptin immunostaining. Furthermore, hormone receptor phenotypes were significantly associated with leptin expression $(P=0.0021)$. All hormone receptor phenotypes were significantly more prevalent in cases with low staining scores except "ER- PR+ HER2"which was more common in cases with high leptin scores. Distributions of ER and HER2 expression were significantly different by leptin immunostaining $(P=0.0279$ and $\mathrm{P}=0.0021$ respectively), while $\mathrm{PR}$ expression was not. Log Rank (Mantel-Cox) test outcomes revealed that significant different survival distributions were observed for different categories of leptin immunostaining scores $(P=0.032)$. Negative leptin immunostaining is related to poor survival significantly (Fig. 2). No significant associations of leptin immunostaining in transformed epithelium with tumor size, vascular invasion and type of tissue (malignant vs control) were observed.

\section{Discussion}

Several serological studies stated evidences that elevated leptin concentration in serum is correlated with breast cancer risk and counted it as an independent risk factor, in addition to its involvement in many malignancy stages including as cell growth, invasion, migration, metastases,

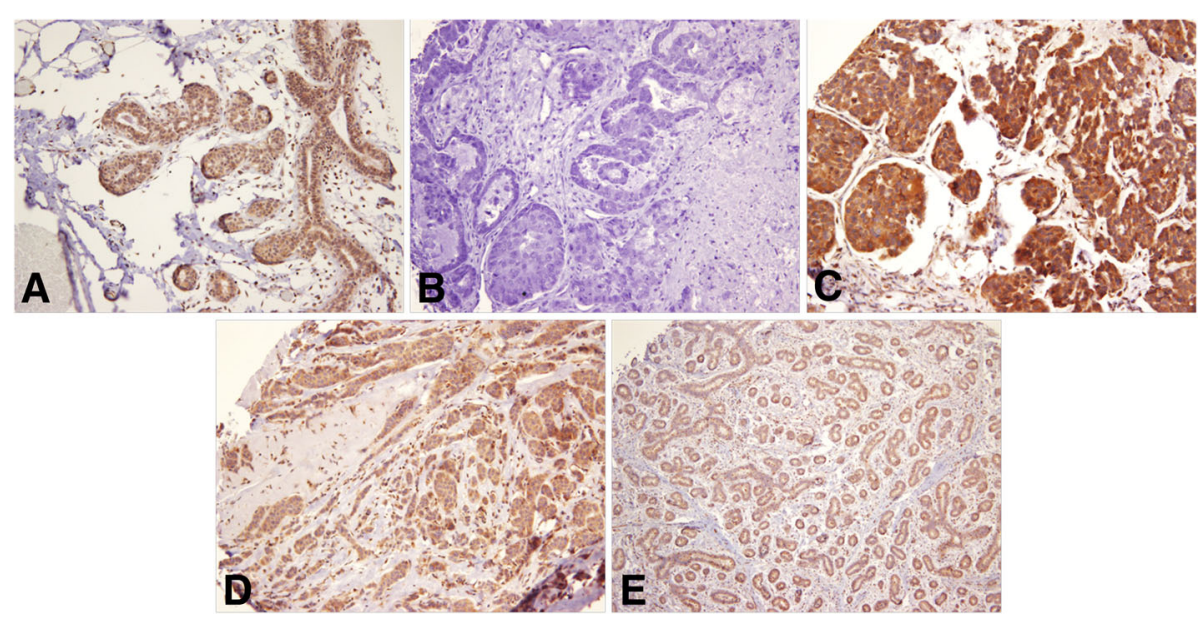

Fig. 1 Granular cytoplasmic expression of leptin in breast cancer. a strong positive staining in normal breast tissue (20 X); b negative stained breast cancer $(20 \mathrm{X})$; c strong positive staining in epithelial cells of breast cancer $(20 \mathrm{X})$; $\mathbf{d}$ weak positive staining in epithelial cells of breast cancer $(20 \mathrm{X})$; e weak positive staining in fibroadenoma (10 X) 


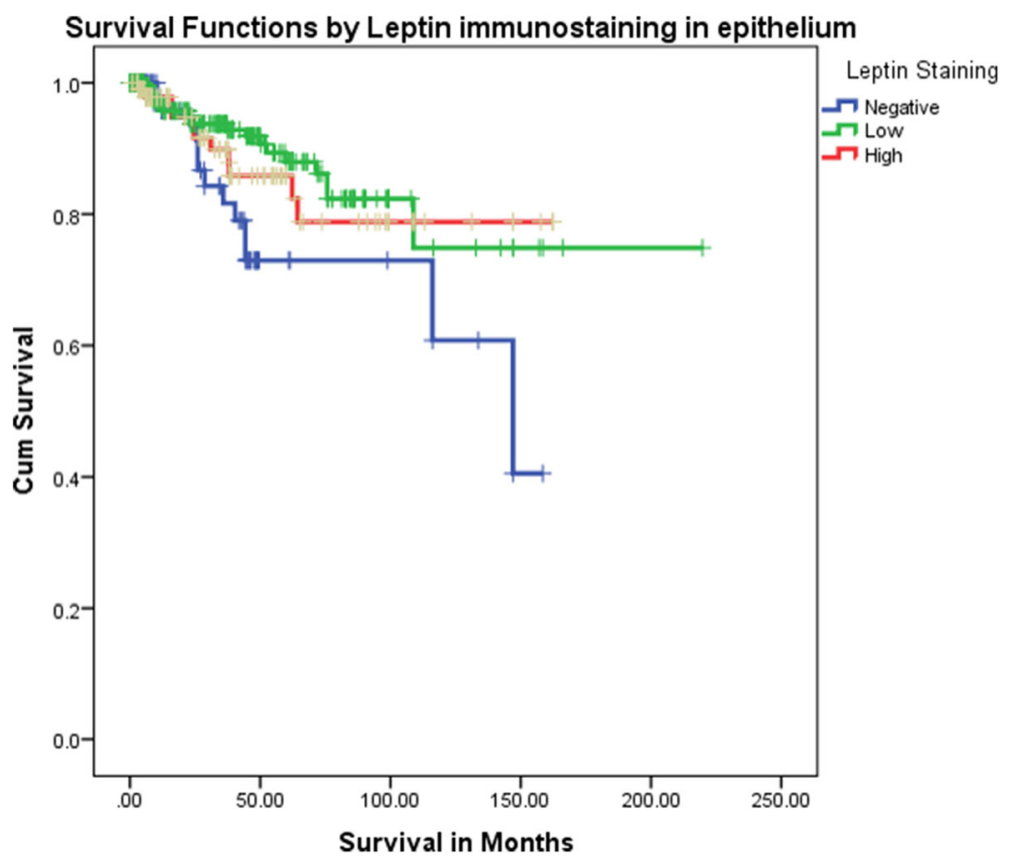

Fig. 2 Kaplan Meier survival curves by pattern of leptin immunostaining shows significantly poor survival behavior associated with negative leptin immunostaining in breast cancer

recurrence and therapy response in some organs such as liver [17], lung [18], stomach [19], thyroid [20], uterus [12], colon [21]. A number of investigations were launched to identify the mechanisms which link leptin with tumor growth and progression of breast cancer [22, 23]. Some studies reported a direct role of leptin in BC development and aggression, and others showed that serum adipocytokines apply their biological roles on recipient tissues and cells not just by typical endocrinological mechanisms but additionally via autocrine or paracrine systems [11, 22-29]. However, leptin expression in mammary tumor tissue is not characteristic of blood leptin levels, but could be a result of the paracrine mechanism [22]. Furthermore, leptin intervenes estrogen effects on malignant tissue via a paracrine pathway, as well as enhances other influences that participate in cell growth and angiogenesis during breast cancer development $[23,30]$. Moreover, leptin autoregulation enhances its signal through motivating its expression and its receptor, thus supports an autocrine mechanism [29]. To the best of our knowledge, few studies evaluated leptin expression in breast cancer tissues (Table 2) [31-40] of which the outcomes failed to confirm the results of leptin serological studies and the correlation of leptin immunoexpression with clinicopathological findings of breast carcinoma patients.

In our report, the incidence of leptin immunostaining (92.6\%) in the 27 control cases, which was seen only in the cytoplasmic space of glandular epithelial cells, is almost similar to the results of Ishikawa, Kitayama and
Nagawa [31] who described positive leptin immunohistochemistry staining in $100 \%$ of noncancerous breast tissue, and higher than those of Caldefie-Chezet and associates [32], Garofalo et al. [33], Jarde and coworkers [35], and Colbert and colleagues [40]. In respect of the percentage of positive breast carcinoma cases for leptin immunoexpression, our results are in line with those of Garofalo and associates [33], Fiorio and coworkers [36], Jarde and associates [37] and Jeong team [39] who detected leptin immunoexpression in $86.4 \%, 79.6 \%, 79.6 \%$ and $83 \%$ of breast carcinomas respectively, but with different immunoreactivity levels; and varied from those of Ishikawa, Kitayama and Nagawa [31], Caldefie-Chezet and associates [32], Kim [38] and Colbert and colleagues [40].

Our investigation is pioneer to report immunohistochemical staining of leptin is considerably correlated with patients' clinicopathological findings such as age, histotype, grade, stage, recurrence, lymph node involvement, hormone receptor phenotype, ER expression, HER2 expression and survival of patients with breast carcinoma. Whereas, all the previous studies (Table 2) did not detect similar correlation except Ishikawa, Kitayama and Nagawa [31] who reported that strong leptin immunostaining is only associated with poor survival; Garofalo and associates [33] associated leptin immunostaining only with high grade tumors; Jeong and colleagues [39] linked leptin expression with histotype of breast cancer; and Colbert and coworkers [40] stated significant relationship with triple negative breast carcinoma. 


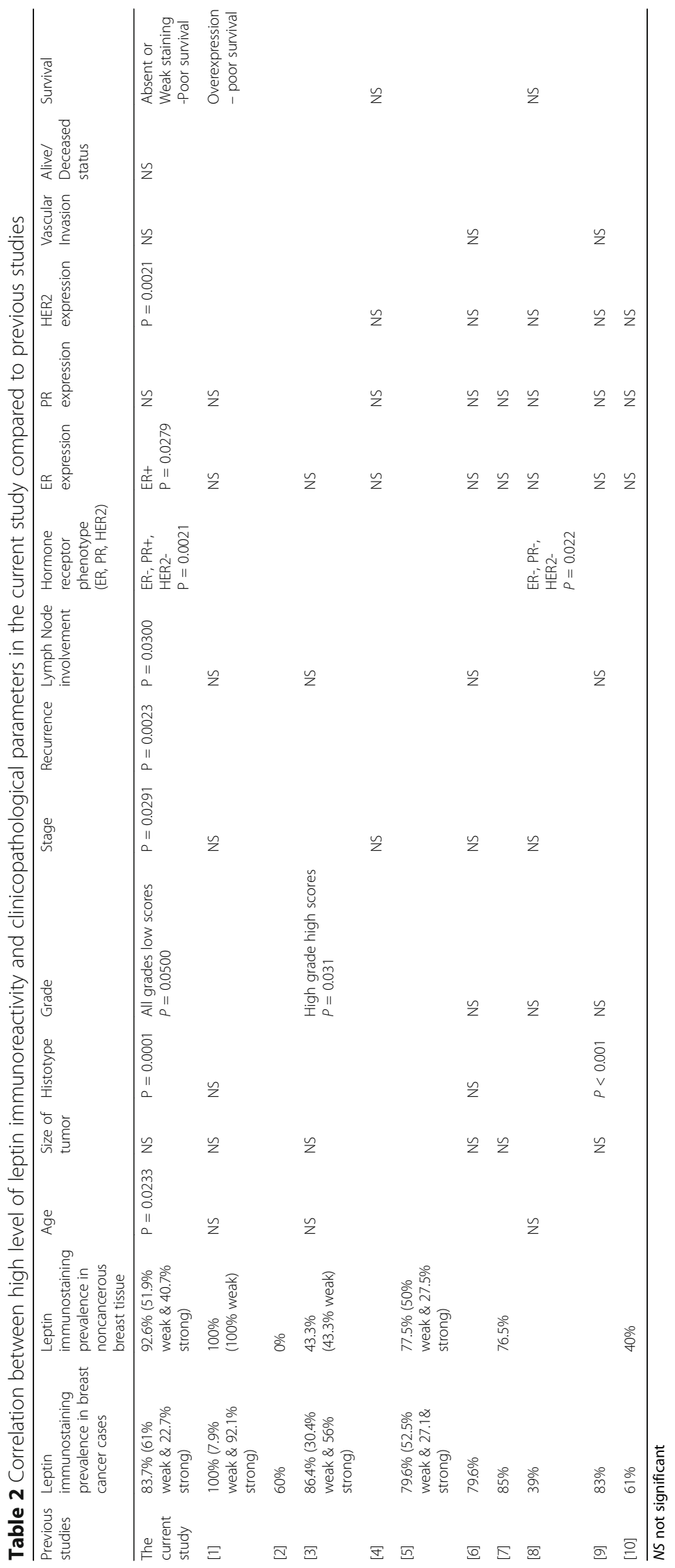


Nevertheless, our results are in agreement with several other reports which have documented that immunoexpression of leptin is linked with one or more of the clinical factors such as tumor stage, infiltration, metastasis, relapse, therapy resistance and bad prognostic outcomes of several tumors including laryngeal cancer [41], esophageal cancer [42], stomach cancer [43], lung cancer [44], and thyroid cancer [45].

Main differences between our report and previous ones can be justified by techniques sensitivity, the diversity of populations, variations in sample size and the semi-quantitative reading of immunostaining. Still, studies with broader panel of cases are certainly of great value for assessing the value of leptin immunostaining in diagnoses and prognoses of breast malignancies.

\section{Conclusions}

Leptin immunostaining is a useful method in supporting the diagnoses and prognoses of breast carcinoma. Our findings proposes that leptin could be a helpful biomarker in identifying the histotype, stage, grade, relapse and prognosis in $\mathrm{BC}$. The association of leptin immunostaining with many clinicopathological factors proposes a role of leptin in $\mathrm{BC}$ progression.

\section{Abbreviations}

BC: Breast cancer; DCIS: Invasive ductal carcinoma; ER: Estrogen receptor; HER2: Human epidermal growth factor receptor 2; Ob: Obese gene; PR: Progesterone receptor; TMA: Tissue microarray; WHO: World Health Organization

\section{Acknowledgements}

This project was funded by the National Plan for Science, Technology and Innovation (MAARIFAH) - King Abdulaziz City for Science and Technology - the Kingdom of Saudi Arabia - award number (10-BIO-1255-03). The authors also acknowledge with thanks, Science and Technology Unit, King Abdulaziz University for technical support.

\section{Funding}

This project was funded by the National Plan for Science, Technology and Innovation (MAARIFAH) - King Abdulaziz City for Science and Technology - the Kingdom of Saudi Arabia - award number (10-BIO-1255-03).

\section{Availability of data and materials}

The datasets used and/or analysed during the current study are available from the corresponding author on reasonable request.

\section{Authors' contributions}

JAI-M, ME and AAl-Dconceived of the study and designed the experiments. LD, KAl-S, and BAl-M performed the technical conduction of the experiments. JAl-M, MNK, AA, NB, SA, PD, BB and MAI-Q analyzed and discussed the results, and drafted the manuscript. All authors read and approved the final manuscript.

\section{Ethics approval and consent to participate}

This study was approved by the Unit of Biomedical Ethics, Research Committee. Document number: 582/34/D. The Unit of Biomedical Ethics did not request consent to participate because this study is a retrospective study which is using archival material.

\section{Consent for publication}

Not applicable.

\section{Competing interests}

The authors declare that they have no competing interests.

\section{Publisher's Note}

Springer Nature remains neutral with regard to jurisdictional claims in published maps and institutional affiliations.

\section{Author details}

${ }^{1}$ Department of Pathology, Rabigh Faculty of Medicine, King Abdulaziz University, Jeddah, Saudi Arabia. ${ }^{2}$ Department of Family and Community Medicine, Rabigh Faculty of Medicine, King Abdulaziz University, Jeddah, Saudi Arabia. ${ }^{3}$ Department of Medical Laboratory Technology, Faculty of Applied Medical Sciences, King Abdulaziz University, Jeddah, Saudi Arabia. ${ }^{4}$ Department of Biological Sciences, Faculty of Science; Immunology Unit, KFMRC, King Abdulaziz University, Jeddah, Saudi Arabia. ${ }^{5}$ Department of Radiology, King Abdulaziz University Hospital, Jeddah, Saudi Arabia. ${ }^{6}$ Faculty of Medicine, King Abdulaziz University, Jeddah, Saudi Arabia. ${ }^{7}$ Department of Human Metabolism, University of Sheffield, Sheffield, UK. ${ }^{8}$ Center of Excellence in Genomic Medicine Research, King Abdulaziz University, Jeddah, Saudi Arabia. ${ }^{9}$ Department of Pathology, Faculty of Medicine, King Abdulaziz University, P.O. Box 80205, Jeddah 21589, Saudi Arabia.

Received: 27 September 2016 Accepted: 30 October 2017

Published online: 09 November 2017

\section{References}

1. Jemal A, Siegel R, Ward E, Hao Y, Xu J, Murray T, Thun MJ. Cancer statistics, 2008. CA Cancer J Clin. 2008;58(2):71-96.

2. American Cancer Society. Cancer Facts \& Figures 2015. Atlanta: American Cancer Society; 2015. https:/www.cancer.org/content/dam/cancer-org/ research/cancer-facts-andstatistics/annual-cancer-facts-and-figures/2015/ cancer-facts-and-figures-2015.pdf.

3. Saudi Cancer Registry. Cancer Registry report 2013. http://www.chs.gov.sa/ Ar/HealthCenters/NCC/CancerRegistry/CancerRegistryReports/2013.pdf.

4. Di Cosimo S, Baselga J. Management of breast cancer with targeted agents: importance of heterogeneity. [corrected]. Nat Rev Clin Oncol. 2010;7(3):139-47.

5. Dent R, Trudeau M, Pritchard KI, Hanna WM, Kahn HK, Sawka CA, Lickley LA, Rawlinson E, Sun P, Narod SA. Triple-negative breast cancer: clinical features and patterns of recurrence. Clin Cancer Res. 2007;13(15 Pt 1):4429-34.

6. Brooks MD, Burness ML, Wicha MS. Therapeutic implications of cellular heterogeneity and plasticity in breast cancer. Cell Stem Cell. 2015;17(3):260-71.

7. Inoue K, Fry EA. Novel molecular markers for breast cancer. Biomark Cancer. 2016;8:25-42

8. Zhang Y, Proenca R, Maffei M, Barone M, Leopold L, Friedman JM. Positional cloning of the mouse obese gene and its human homologue. Nature. 1994; 372(6505):425-32.

9. Baratta M. Leptin-from a signal of adiposity to a hormonal mediator in peripheral tissues. Med Sci Monit. 2002;8(12):RA282-92.

10. Allison MB, Myers MG Jr. 20 years of leptin: connecting leptin signaling to biological function. J Endocrinol. 2014;223(1):T25-35.

11. Dubois V, Jarde T, Delort L, Billard H, Bernard-Gallon D, Berger E, Geloen A, Vasson MP, Caldefie-Chezet F. Leptin induces a proliferative response in breast cancer cells but not in normal breast cells. Nutr Cancer. 2014;66(4):645-55

12. Zhou X, Li H, Chai Y, Liu Z. Leptin inhibits the apoptosis of endometrial carcinoma cells through activation of the nuclear factor kappaB-inducing Kinase//kappaB Kinase pathway. Int J Gynecol Cancer. 2015;25(5):770-8.

13. Lipsey CC, Harbuzariu A, Daley-Brown D, Gonzalez-Perez RR. Oncogenic role of leptin and notch interleukin-1 leptin crosstalk outcome in cancer. World J Methodol. 2016;6(1):43-55.

14. Mantzoros CS, Magkos F, Brinkoetter M, Sienkiewicz E, Dardeno TA, Kim SY, Hamnvik OP, Koniaris A. Leptin in human physiology and pathophysiology. Am J Physiol Endocrinol Metab. 2011;301(4):E567-84.

15. Luhn P, Dallal CM, Weiss JM, Black A, Huang WY, Lacey JV Jr, Hayes RB, Stanczyk FZ, Wentzensen N, Brinton LA. Circulating adipokine levels and endometrial cancer risk in the prostate, lung, colorectal, and ovarian cancer screening trial. Cancer Epidemiol Biomark Prev. 2013;22(7):1304-12.

16. Al-Maghrabi J, Emam E, Gomaa W, Saggaf M, Buhmeida A, Al-Qahtani M, AlAhwal M: C-MET immunostaining in colorectal carcinoma is associated with local disease recurrence. BMC Cancer 2015, 15:676.

17. Saxena NK, Sharma D, Ding X, Lin S, Marra F, Merlin D, Anania FA. Concomitant activation of the JAK/STAT, PI3K/AKT, and ERK signaling is involved in leptin-mediated promotion of invasion and migration of hepatocellular carcinoma cells. Cancer Res. 2007;67(6):2497-507. 
18. Zheng XJ, Yang ZX, Dong YJ, Zhang GY, Sun MF, An XK, Pan LH, Zhang SL. Downregulation of leptin inhibits growth and induces apoptosis of lung cancer cells via the notch and JAK/STAT3 signaling pathways. Biol Open. 2016;5(6):794-800

19. Lee KN, Choi HS, Yang SY, Park HK, Lee YY, Lee OY, Yoon BC, Hahm JS, Paik SS. The role of leptin in gastric cancer: clinicopathologic features and molecular mechanisms. Biochem Biophys Res Commun. 2014;446(4):822-9

20. Yang YC, Chin YT, Hsieh MT, Lai HY, Ke CC, Crawford DR, Lee OK, Fu E, Mousa SA, Grasso P, et al. Novel leptin OB3 peptide-induced signaling and progression in thyroid cancers: comparison with leptin. Oncotarget. 2016; 7(19):27641-54.

21. Ogunwobi OO, Beales IL. Cyclo-oxygenase-independent inhibition of apoptosis and stimulation of proliferation by leptin in human colon cancer cells. Dig Dis Sci. 2007;52(8):1934-45.

22. Vona-Davis L, Rose DP. Adipokines as endocrine, paracrine, and autocrine factors in breast cancer risk and progression. Endocr Relat Cancer. 2007;14(2):189-206.

23. Gonzalez RR, Cherfils S, Escobar M, Yoo JH, Carino C, Styer AK, Sullivan BT, Sakamoto H, Olawaiye A, Serikawa T, et al. Leptin signaling promotes the growth of mammary tumors and increases the expression of vascular endothelial growth factor (VEGF) and its receptor type two (VEGF-R2). J Biol Chem. 2006:281(36):26320-8.

24. Li K, Wei L, Huang Y, Wu Y, Su M, Pang X, Wang N, Ji F, Zhong C, Chen T. Leptin promotes breast cancer cell migration and invasion via IL-18 expression and secretion. Int J Oncol. 2016;48(6):2479-87.

25. Assiri AM, Kamel HF. Evaluation of diagnostic and predictive value of serum adipokines: Leptin, resistin and visfatin in postmenopausal breast cancer. Obes Res Clin Pract. 2016;10(4):442-53.

26. Strong AL, Ohlstein JF, Biagas BA, Rhodes LV, Pei DT, Tucker HA, Llamas C, Bowles AC, Dutreil MF, Zhang $S$, et al. Leptin produced by obese adipose stromal/stem cells enhances proliferation and metastasis of estrogen receptor positive breast cancers. Breast Cancer Res. 2015;17:112.

27. Ando S, Barone I, Giordano C, Bonofiglio D, Catalano S. The multifaceted mechanism of Leptin Signaling within tumor microenvironment in driving breast cancer growth and progression. Front Oncol. 2014:4:340.

28. Mohammadzadeh G, Ghaffari MA, Bafandeh A, Hosseini SM. Association of serum soluble leptin receptor and leptin levels with breast cancer. J Res Med Sci. 2014;19(5):433-8.

29. Chen C, Chang YC, Liu CL, Chang KJ, Guo IC. Leptin-induced growth of human ZR-75-1 breast cancer cells is associated with up-regulation of cyclin D1 and C-Myc and down-regulation of tumor suppressor p53 and p21WAF1/CIP1. Breast Cancer Res Treat. 2006;98(2):121-32.

30. Schmidt S, Monk JM, Robinson LE, Mourtzakis M. The integrative role of leptin, oestrogen and the insulin family in obesity-associated breast cancer: potential effects of exercise. Obes Rev. 2015;16(6):473-87.

31. Ishikawa M, Kitayama J, Nagawa H. Enhanced expression of leptin and leptin receptor (OB-R) in human breast cancer. Clin Cancer Res. 2004;10(13):4325-31.

32. Caldefie-Chezet F, Damez M, de Latour M, Konska G, Mishellani F, Fusillier C, Guerry M, Penault-Llorca F, Guillot J, Vasson MP. Leptin: a proliferative factor for breast cancer? Study on human ductal carcinoma. Biochem Biophys Res Commun. 2005;334(3):737-41.

33. Garofalo C, Koda M, Cascio S, Sulkowska M, Kanczuga-Koda L, Golaszewska J, Russo A, Sulkowski S, Surmacz E. Increased expression of leptin and the leptin receptor as a marker of breast cancer progression: possible role of obesity-related stimuli. Clin Cancer Res. 2006;12(5):1447-53.

34. Kim Y, Kim SY, Lee JJ, Seo J, Kim YW, Koh SH, Yoon HJ, Cho KS. Effects of the expression of leptin and leptin receptor (OBR) on the prognosis of early-stage breast cancers. Cancer Res Treat. 2006;38(3):126-32.

35. Jarde T, Caldefie-Chezet F, Damez M, Mishellany F, Penault-Llorca F, Guillot J, Vasson MP. Leptin and leptin receptor involvement in cancer development: a study on human primary breast carcinoma. Oncol Rep. 2008;19(4):905-11.

36. Fiorio E, Mercanti A, Terrasi M, Micciolo R, Remo A, Auriemma A, Molino A, Parolin V, Di Stefano B, Bonetti F, et al. Leptin/HER2 crosstalk in breast cancer: in vitro study and preliminary in vivo analysis. BMC Cancer. 2008:8:305.

37. Jarde T, Caldefie-Chezet F, Damez M, Mishellany F, Perrone D, Penault-Llorca F, Guillot J, Vasson MP. Adiponectin and leptin expression in primary ductal breast cancer and in adjacent healthy epithelial and myoepithelial tissue. Histopathology. 2008;53(4):484-7.

38. Kim HS. Leptin and leptin receptor expression in breast cancer. Cancer Res Treat. 2009:41(3):155-63.
39. Jeong YJ, Bong JG, Park SH, Choi JH, Oh HK. Expression of leptin, leptin receptor, adiponectin, and adiponectin receptor in ductal carcinoma in situ and invasive breast cancer. J Breast Cancer. 2011;14(2):96-103.

40. Colbert LS, Wilson K, Kim S, Liu Y, Oprea-llies G, Gillespie C, Dickson T, Newman G, Gonzalez-Perez RR. NILCO biomarkers in breast cancer from Chinese patients. BMC Cancer. 2014;14:249.

41. Gallina S, Sireci F, Lorusso F, Dib DV, Speciale R, Marchese D, Costantino C, Napoli G, Tessitore V, Cucco D, et al. The immunohistochemical peptidergic expression of leptin is associated with recurrence of malignancy in laryngeal squamous cell carcinoma. Acta Otorhinolaryngol Ital. 2015;35(1):15-22.

42. Duan $X$, Tang $P$, Zhang $H$, Yu Z. Expression of leptin and adiponectin in esophageal squamous cell carcinoma and their clinical significance. Zhonghua Zhong Liu Za Zhi. 2014;36(11):839-43.

43. Bain GH, Collie-Duguid E, Murray Gl, Gilbert FJ, Denison A, McKiddie F, Ahearn T, Fleming I, Leeds J, Phull $P$, et al. Tumour expression of leptin is associated with chemotherapy resistance and therapy-independent prognosis in gastro-oesophageal adenocarcinomas. Br J Cancer. 2014; 110(6):1525-34.

44. Xu YJ, Shao YF, Zhao X, Geng YT, Wang K, Yin YM. Expression and clinical significance of leptin, the functional receptor of leptin (OB-Rb) and HER-2 in non-small-cell lung cancer: a retrospective analysis. J Cancer Res Clin Oncol. 2011:137(12):1841-8.

45. Fan YL, Li XQ. Expression of leptin and its receptor in thyroid carcinoma: distinctive prognostic significance in different subtypes. Clin Endocrinol. 2015;83(2):261-7.

\section{Submit your next manuscript to BioMed Central and we will help you at every step:}

- We accept pre-submission inquiries

- Our selector tool helps you to find the most relevant journal

- We provide round the clock customer support

- Convenient online submission

- Thorough peer review

- Inclusion in PubMed and all major indexing services

- Maximum visibility for your research

Submit your manuscript at www.biomedcentral.com/submit
) Biomed Central 